Library, N. W. Blde.

MAY 111949

\title{
kaken from the Library.
}

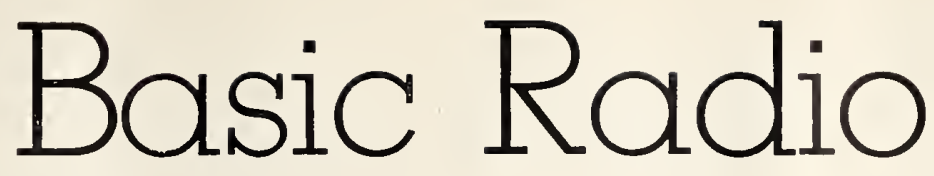

Propagation

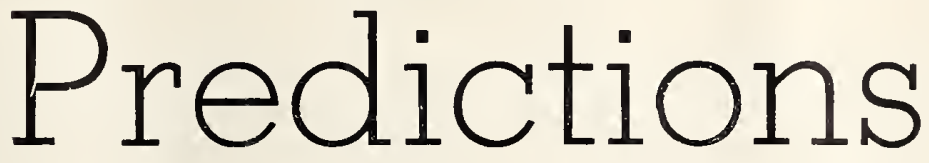

$\mathrm{F} \bigcirc \mathrm{R} \quad \mathrm{A} U \mathrm{GUST} 1949$

Three Months in Advance

Issued May 1949

CRPL Series D

$\mathrm{Number} 57$ 


\section{The Central Radio Propagation Laboratory}

The propagation of radio naves over long distances defends on their refection from the ionosphere, the electrically conducting layers in the earth's upper at mosphere. The characteristics of these layers are continuously changing. For regular and reliable communication, it is therefore necessary to collect and analvze ionospheric data from stations all over the world in order that predictions of usable frequencies between any two places at any hour can be made. During the war, the United States Joint Communications Board set up the Interservice Radio Propagation Laboratory at the National Bureau of Standards to centralize ionospheric work and predictions for the Armed Forces of the United States.

On May 1, 1946, this activity returned to peacetime status as the Central Radio Propagation Laboratory of the National Bureau of Standards. Designed to act as a permanent centralizing agency for propagation predictions and studies, analogous in the field of radio to the reports of the Weather Bureau in the field of meteorology, the Central Radio Propagation Laboratory was established in cooperation with the many Government agencies vitally concerned with communication and radio propagation problems. These agencies are represented on an Executive Council which guides the work of the Laboratory; included are the Department of the Army, Department of the Navy, Department of the Air Force, Civil Aeronautics Administration, Federal Communications Commission, Department of State, Coast Guard, Coast and Geodetic Survey, and the Weather Bureau. In addition, industry is represented by the Radio Technical Planning Board, while the Carnegie Institution of Washington serves in an advisory capacity and the Research and Development Board has designated an observer.

The Central Radio Propagation Laboratory receives and analyzes data from approximately 60 stations located throughout the world, including 13 domestic and 8 overseas stations which are operated either directly or under contract by the National Bureau of Standards. Ionospheric data and predictions are disseminated to the armed forces, commercial users, scientists, and laboratories. The kasic ionospheric research of the Laboratory includes theoretical and experimental studies of maximum usable frequencies, ionospheric absorption, long-time variations of radio propagation characteristics, the effects of the sun on radio propagation, and the relation between radio disturbance and geomagnetic variation. In the microwave field, the Laboratory is investigating the relation between radio propagation and weather phenomena, as well as methods by which predictions can be made and radio communications improved in this portion of the radiofrequency spectrum. Another phase of the Laboratory's work is the development and maintenance of standards and methods of measurement of many basic electrical quantities throughout the entire frequency spectrum.

\section{Basic Radio Propagation Predictions}

The CRPL Series D, Basic Radio Propagation Predictions, is issued monthly as an aid in the determination of the best sky-wave frequencies over any path at any time of day for average conditions for the month of prediction, 3 months in advance. Charts of extraordinary-wave critical frequency for the $F 2$ layer, of maximum usable frequency for a transmission distance of $4,000 \mathrm{~km}$, and of percentage of time occurrence for transmission by sporadic $E$ in excess of $15 \mathrm{Mc}$, for a distance of $2,000 \mathrm{~km}$, are included.

Beginning with the July 1946 issue (CRPL-D23) the CRPL-D series, "Basic Radio Propagation Predictions," is available on a purchase basis from the Superintendent of Documents, U. S. Government Printing Office, Washington 25, D. C., on the following terms:

Single copy _...

(CRPL-D23 through D36, 15 cents per copy)

Annual subscription (12 issues)

$\$ 1.00$

(To foreign countries not extending franking privileges, $\$ 1.25$ )

The rules of the Superintendent of Documents require that remittances be made in advance, either by coupons sold in sets of 20 for $\$ 1$ and good until used, or by check or money order payable to the Superintendent of Documents. Currency, if used, is at sender's risk. Postage stamps, foreign money, and defaced or smooth coins are not acceptable. Postage is not required in the United States, to United States possessions, and to countries extending franking privileges. Remittanccs from foreign countries should be by international money order payable to the Superintendent of Documents or by draft on a United States bank.

Address subscriptions, remittances, and all inquiries relating thercto, to the Superintendent of Documents, U. S. Government Printing Office, Washington 25, D. C. 


\section{U. S. DEPARTMENT OF COMMERCE \\ Charles Sawyer, Secretary}

NATIONAL BUREAU OF STANDARDS

E. U. Condon, Director
Ma y 1949

CRPL Series D

$\mathrm{N}$ u m ber 57

\section{BASIC RADIO PROPAGATION PREDICTIONS}

For August 1949

Three Months in Advance

\section{Introduction}

Beginning with the September 1947 issue, the CRPL-D series, "Basic Radio Propagation Predictions," issued by the National Bureau of Standards, contains contour charts of F2-zero-MUF and F24000-MUF for each of the three zones, W, I, and E, into which the world is divided for the purpose of taking into consideration the variation of the characteristics of the F2 layer with longitude (figs. 1 to 6 ); the world-wide contour chart of E-2000-MUF (fig. 7); the contour chart of median fEs (fig. 8); and the chart showing percentage of time occurrence for $E s-2000-\mathrm{MUF}$ in excess of 15 Mc (fig. 9).

Methods for using these charts are given in Circular 465 of the National Bureau of Standards, entitled "Instructions for the Use of Basic Radio Propagation Predictions," and available from the Superintendent of Documents, U. S. Government Printing Office, Washington 25, D. C., price 25 cents (foreign, 35 cents). Requests for this manual from members of the Army, Navy, or Air Force should be sent to the proper service address as follows. For the Army and Air Force: Office of the Chief Signal Officer, Department of the Army, Washington 25, D. C., Attention: SIGOL-2. For the Navy: Chief of Naval Operations, Department of the Navy, Washington 25, D. C. (CNC-20-Q).

Following figure 9 of each issue, sets of auxiliary figures (nos. 1, 2, 11, 12, NBS Circular 465) or forms CRPI-AF and $\mathrm{AH}$ are given in rotation, two in each issue of CRPL Series D. They are necessary or useful for the preparation of tables and graphs of MUF and FOT (OWF), as explained in NBS Circular 465 .

The charts in this issue were constructed from data through February 1949, together with a predicted smoothed 12-month running-average Zürich sunspot number of 111, centered on August 1949.

Attention is invited to the blank form at the end of this publication, for use in reporting the accuracy of the predictions of MUF and FOT (OWF) as given in this report. Communications should be addressed to Central Radio Propagation Laboratory, National Bureau of Standards, Washington 25, D. C.

Information concerning the theory of radio wave propagation, measurement technics, structure of the ionosphere, ionospheric variations, prediction methods, absorption, field intensity, radio noise, lowest required radiated power and lowest useful high frequency is given in Circular 462 of the National Bureau of Standards, "Ionospheric Radio Propagation." This Circular is available from the Superintendent of Documents, price $\$ 1.00$ (foreign, $\$ 1.25$ ). 


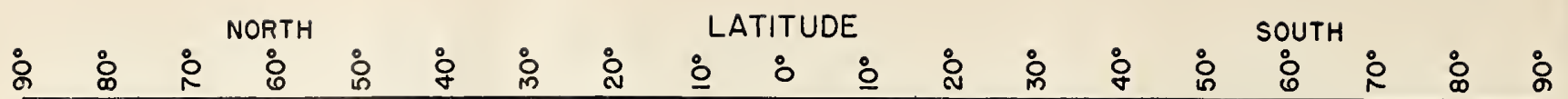

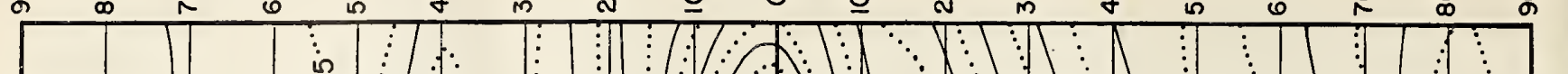

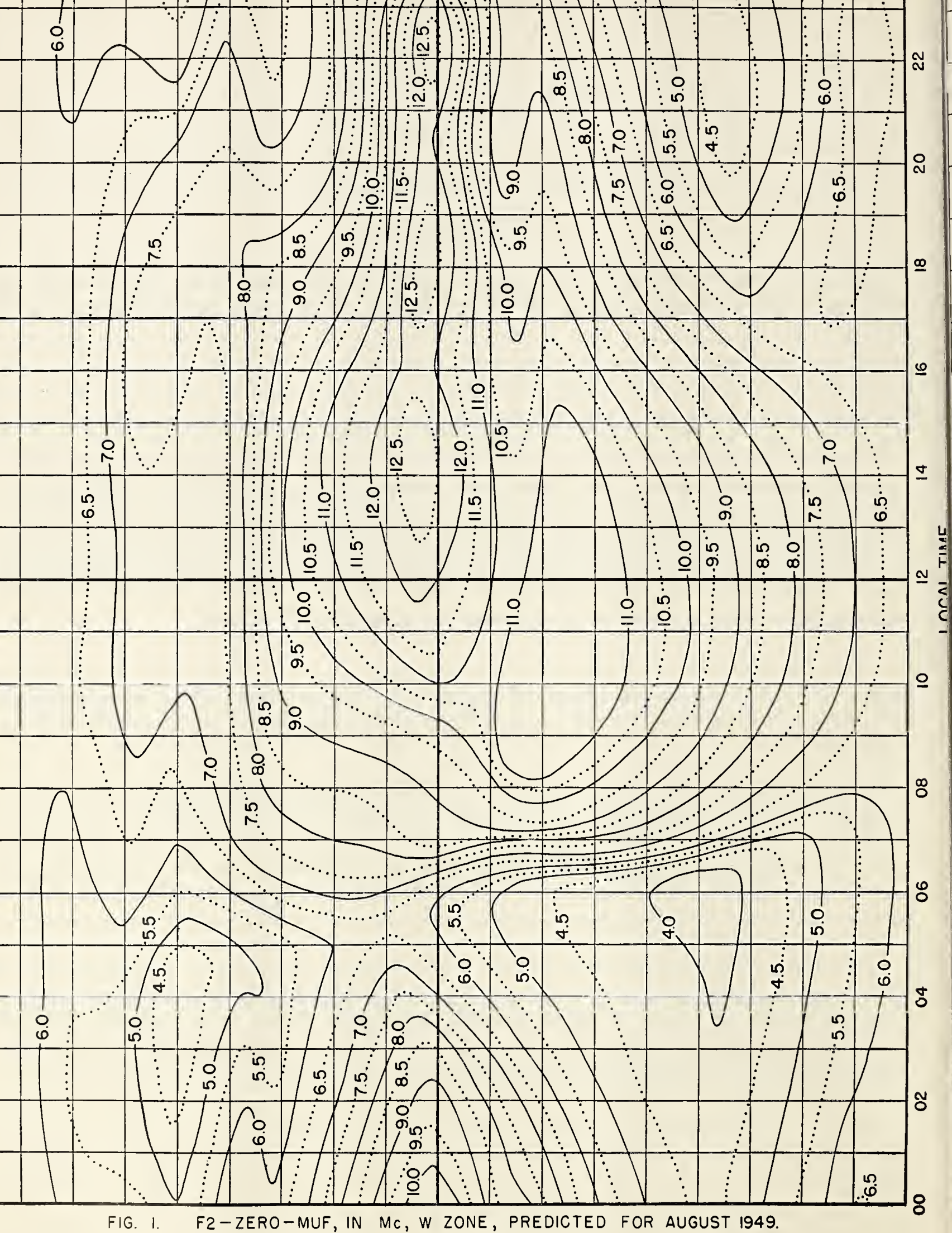


NORTH LATITUDE

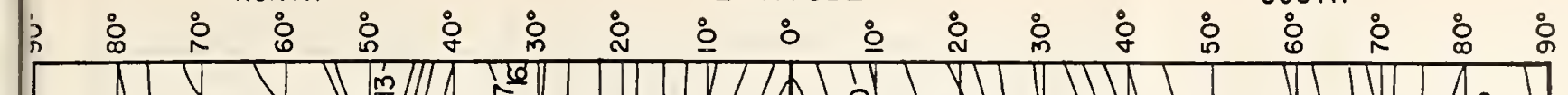
$=$

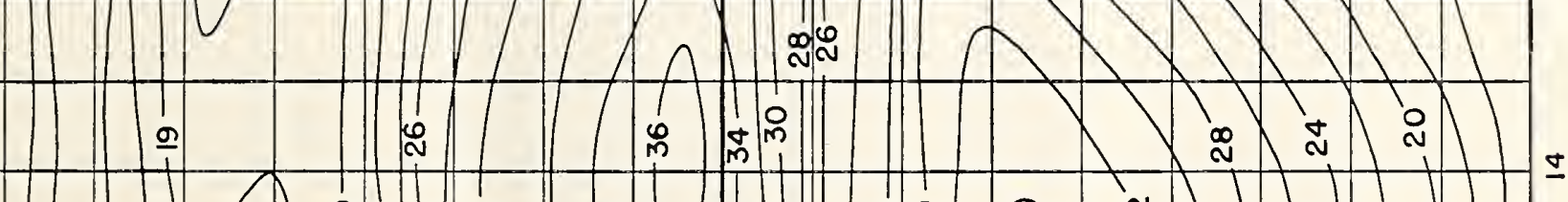

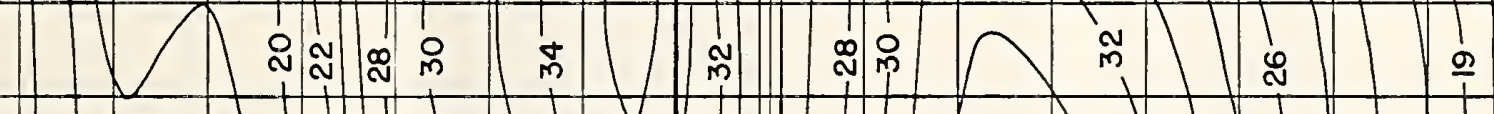

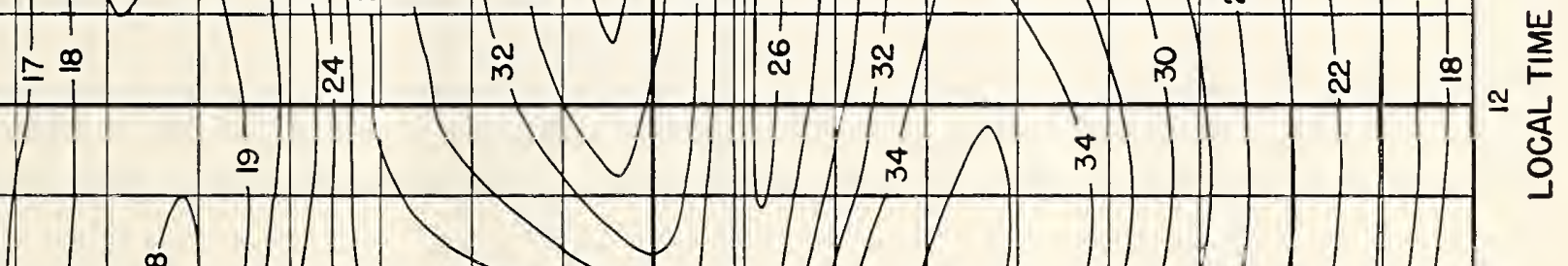
@

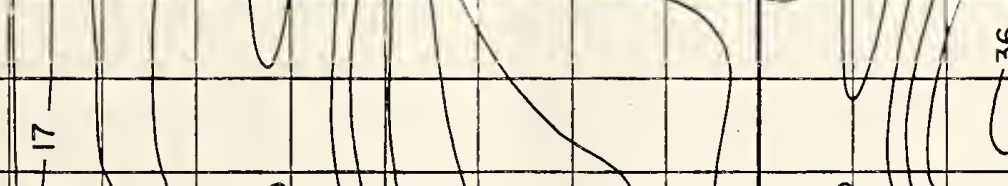
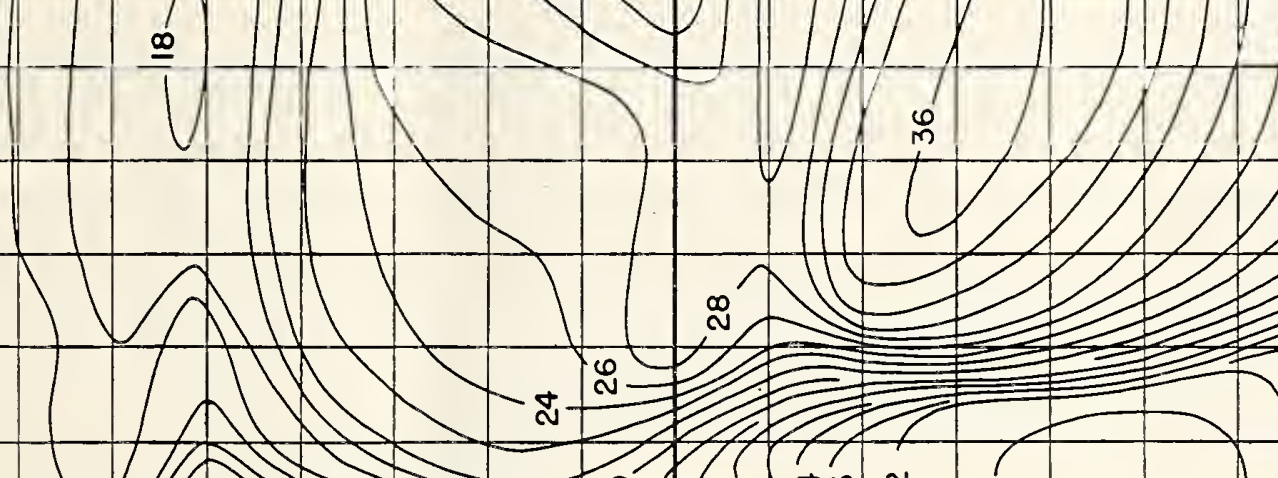

$\infty$

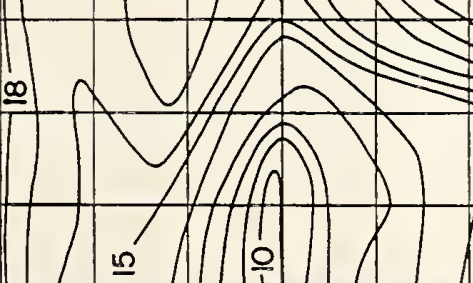

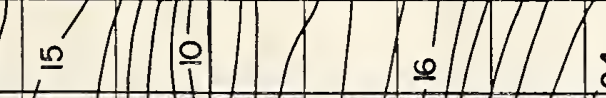

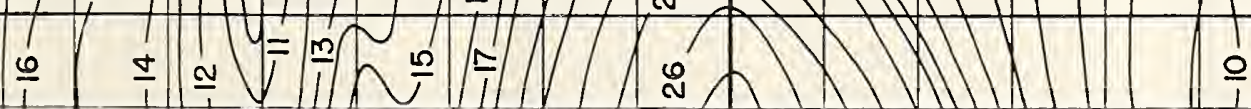

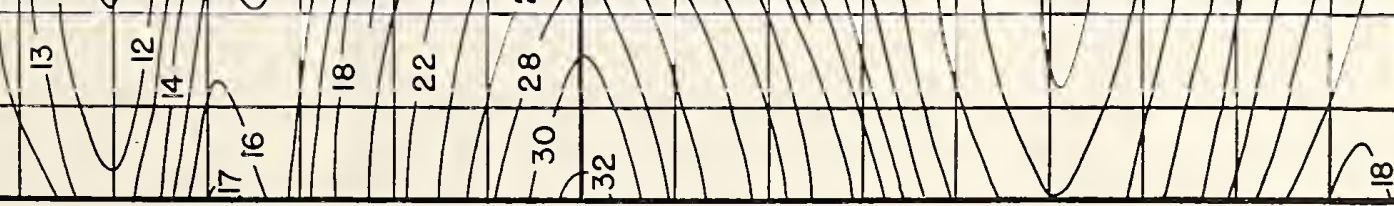
FIG. 2. F2-4000-MUF, IN MC, W ZONE, PREDICTED FOR AUGUST 1949. 


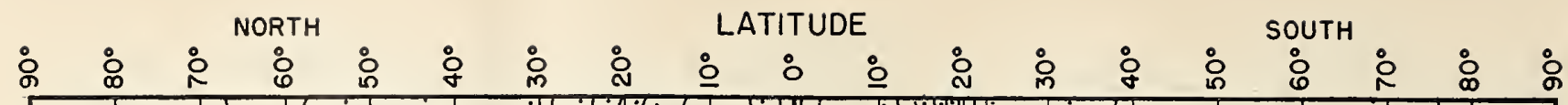
(1)

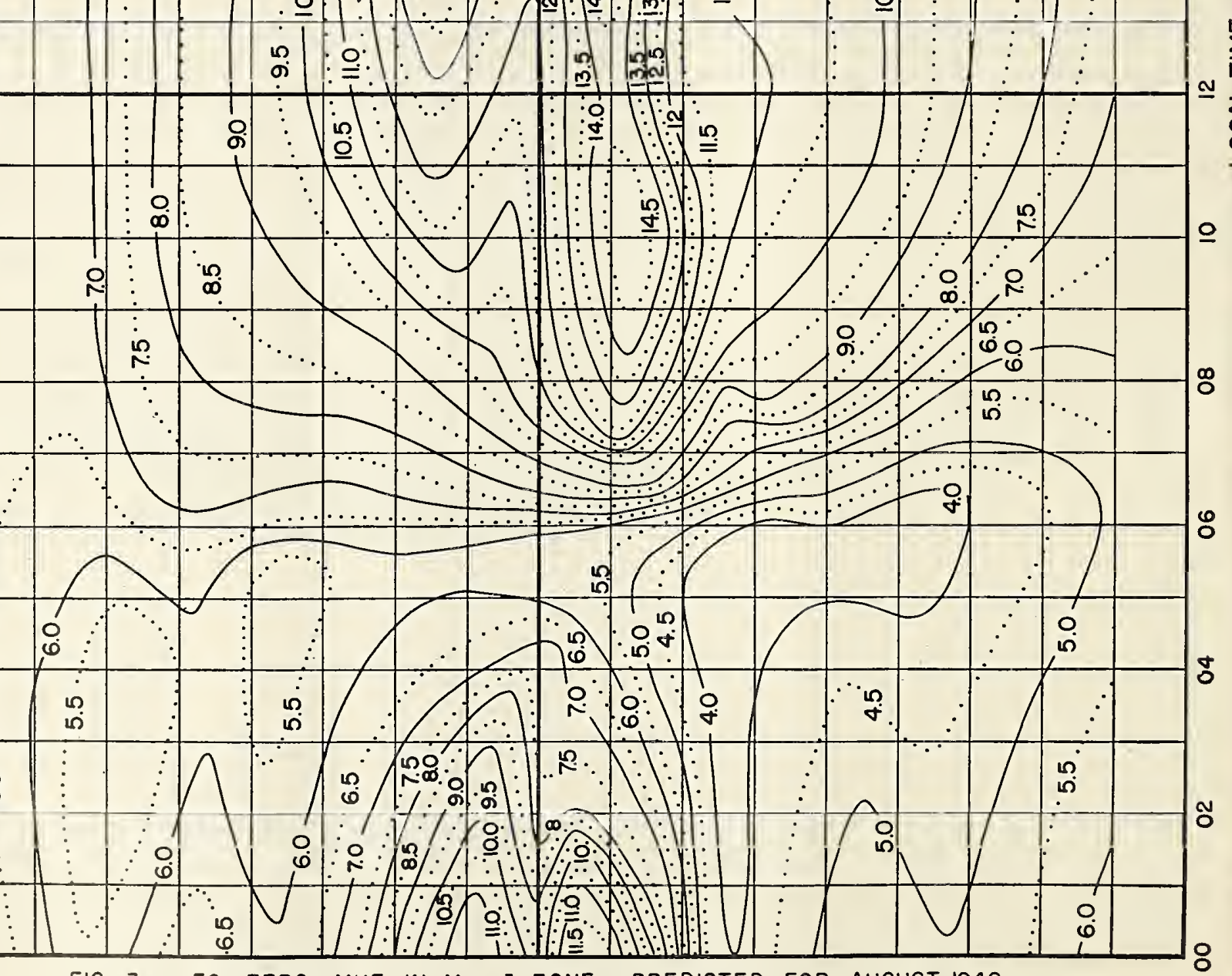

FIG. 3. F2-ZERO-MUF, IN MC, I ZONE, PREDICTED FOR AUGUST 1949. 
$\therefore$ NORTH $\therefore \quad \therefore$ LATITUDE

SOUTH

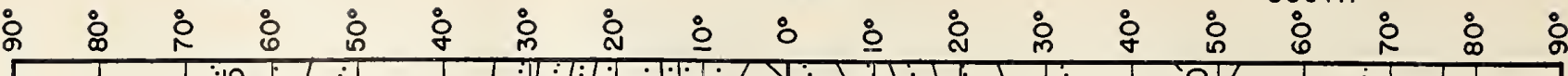

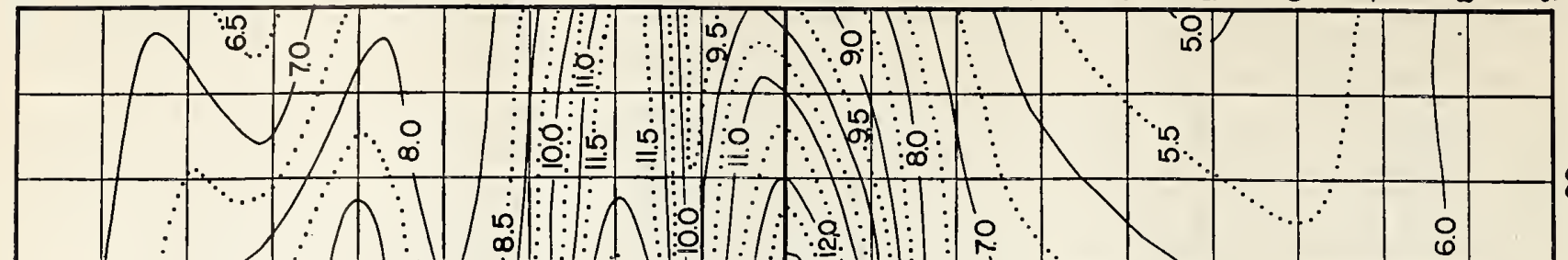
กิ

오
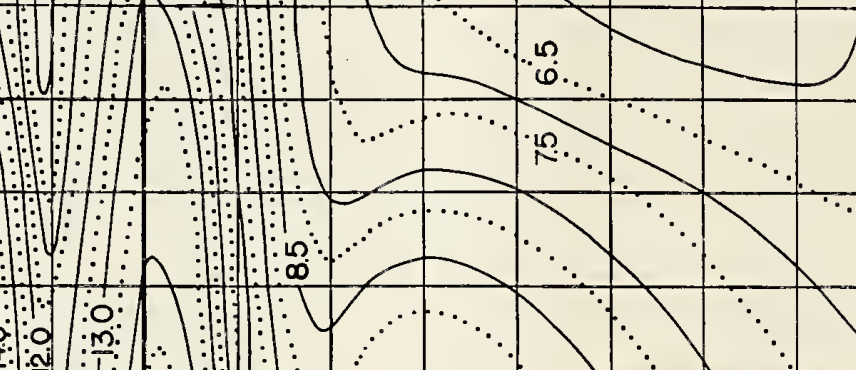

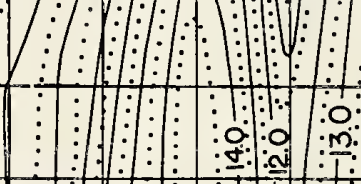

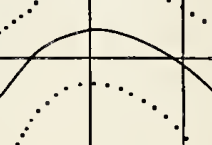

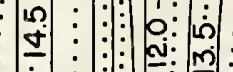

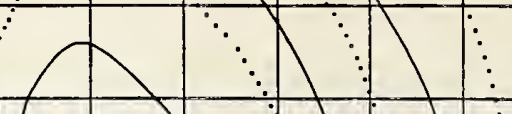

\begin{tabular}{c|c}
0 & $\vdots$ \\
$\vdots$ & $\vdots$ \\
$\vdots$ & $\vdots$ \\
$\vdots$ & 0 \\
\hline & 0 \\
\hline
\end{tabular}

$\stackrel{\leftrightarrow}{\stackrel{0}{0}}$

$\stackrel{0}{\circ}$

$\vdots$

\begin{tabular}{c|c|c} 
& $\vdots$ & $\vdots$ \\
0 & $\vdots$ & $\infty$ \\
\hline
\end{tabular}

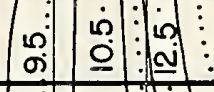

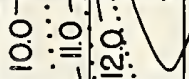

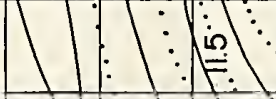

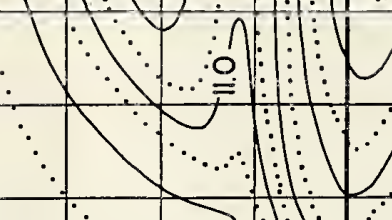

于

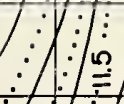

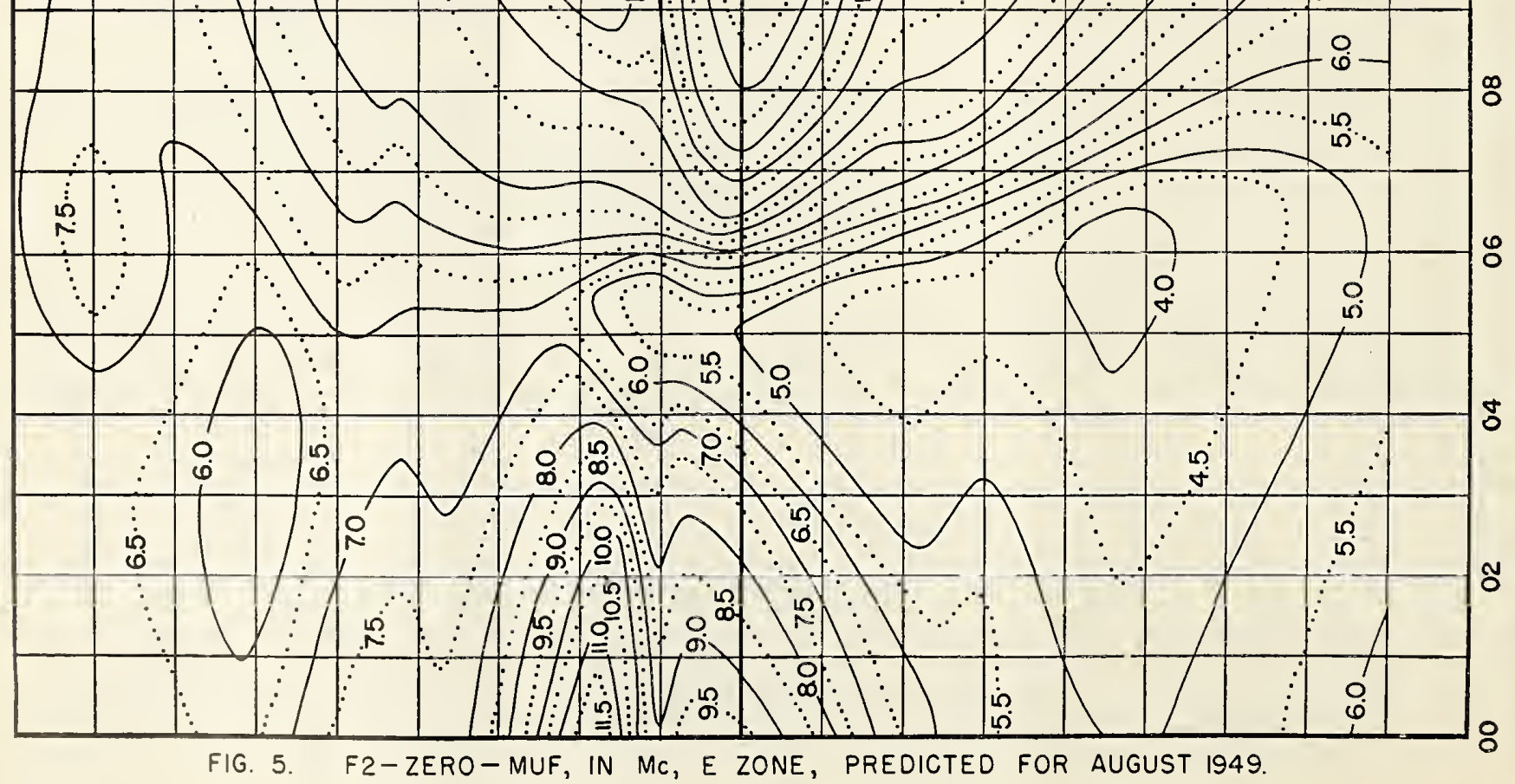


NORTH LATITUDE $\stackrel{1}{0}$ (1) $\underline{\underline{O}}$ $\approx$.

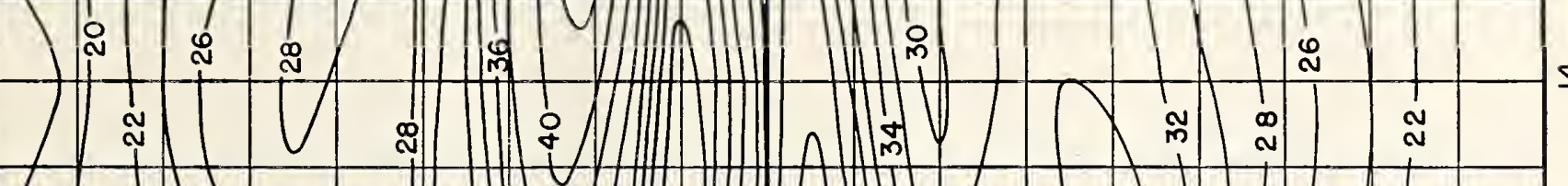
(1)

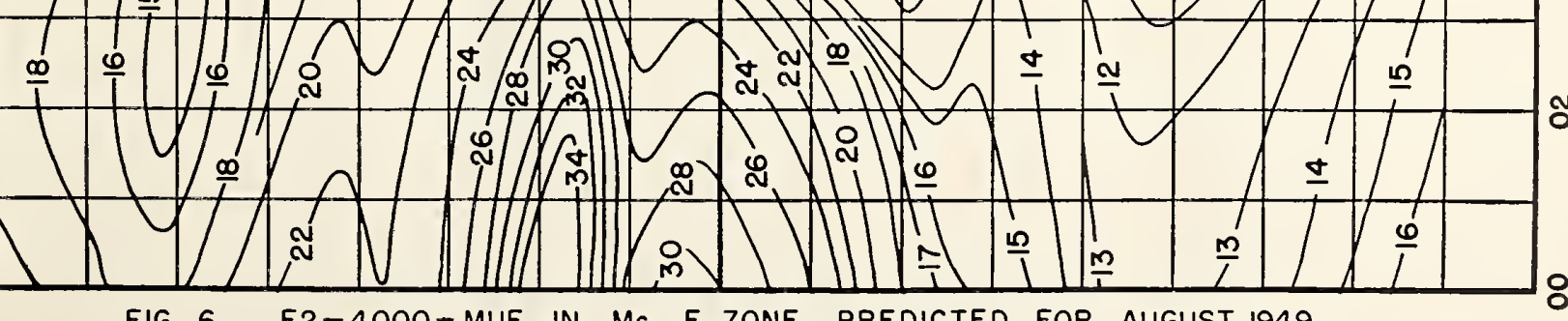
FIG. 6. F2-4000-MUF, IN Mc, E ZONE, PREDICTED FOR AUGUST 1949. 
NORTH LATITUDE $: \circ O$ \&

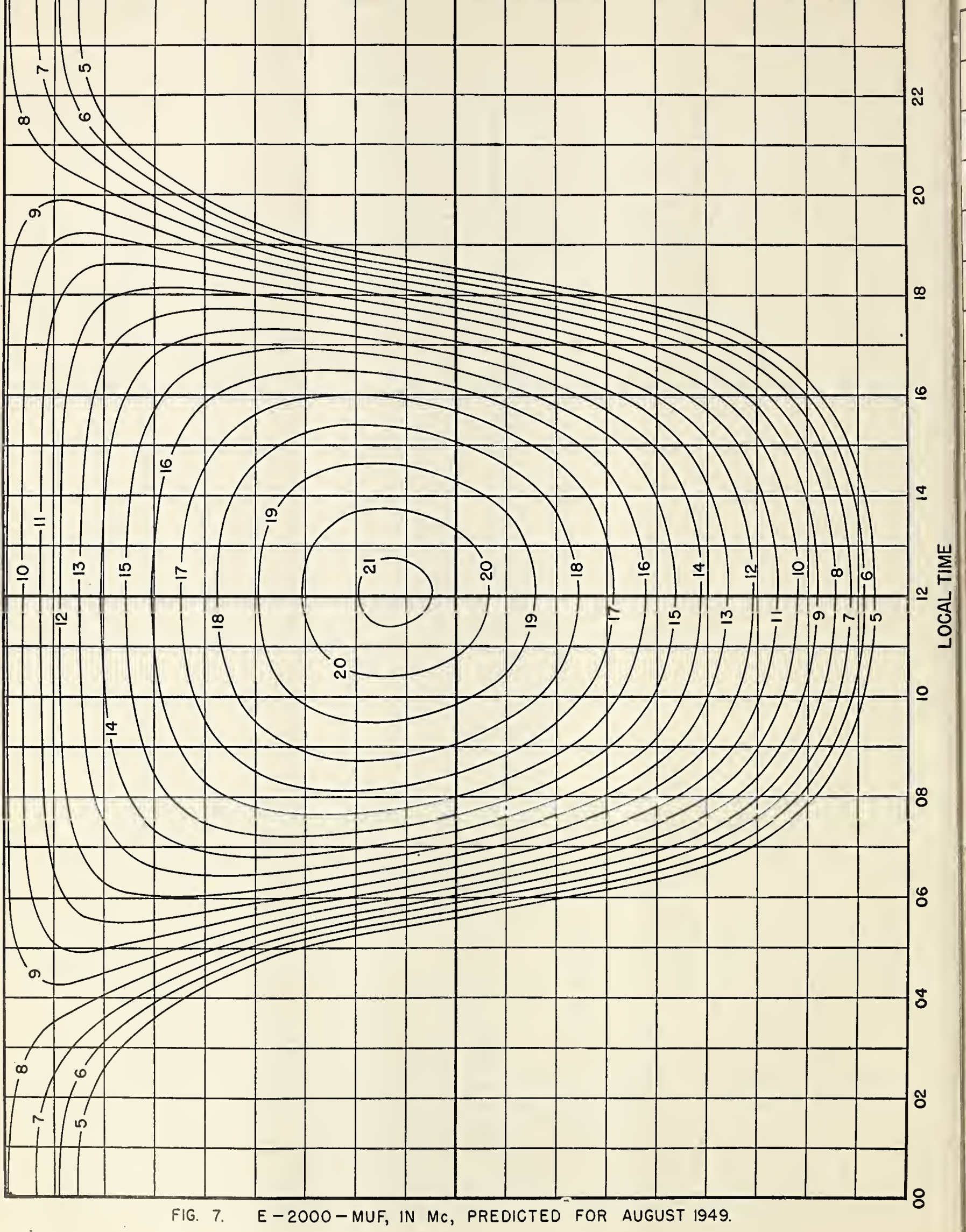





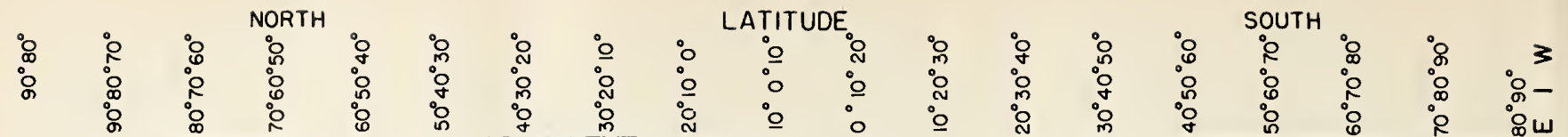

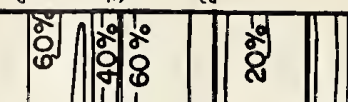

1

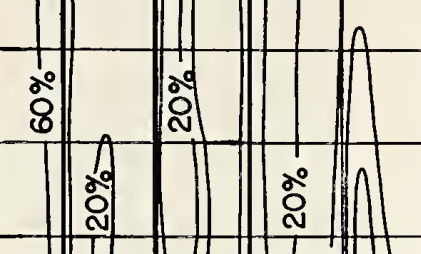

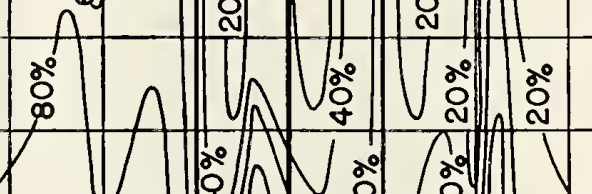
$\sim$
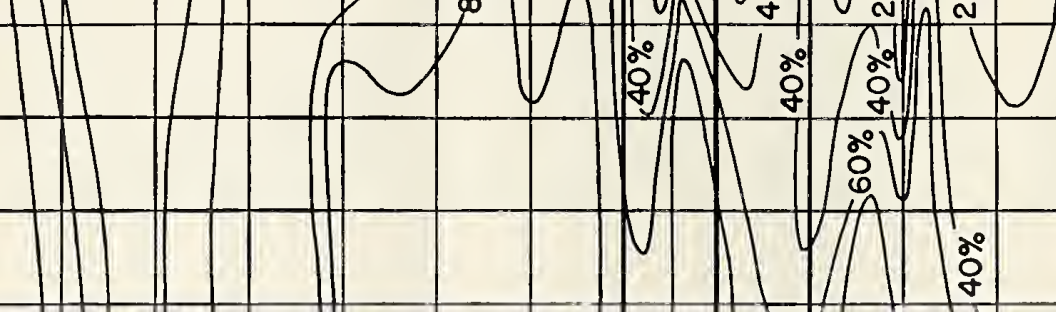

:

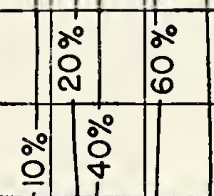

10000

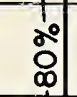

: : : :

오

웅 $\underline{\underline{\omega}}$

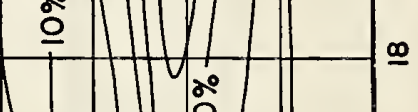

(1)

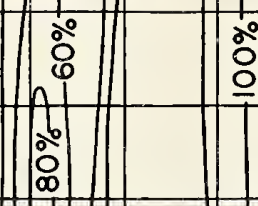

ஓ̊ำ

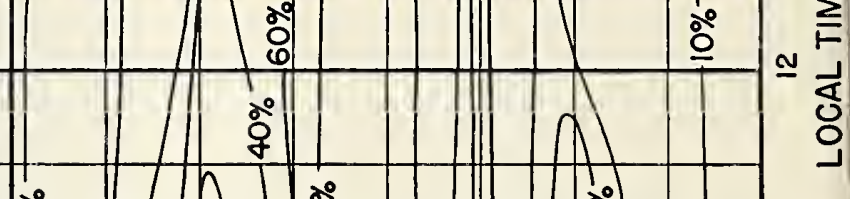

○̊ำ

1

VN

$\because$ : $:$

(1)

$\stackrel{8}{\circ}$

으

음

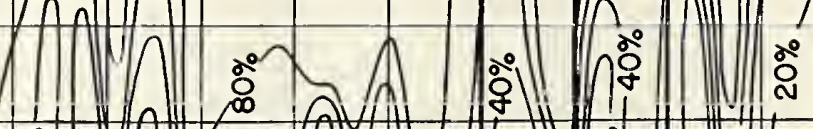
| 
$1 \mathrm{~km}=0.62137$ mile $=0.53961$ naut $\mathrm{mi}$.

1 mile $=1.60935 \mathrm{~km}=0.86836$ nout. $\mathrm{mi}$.

I nout. $\mathrm{mi} .=1.85325 \mathrm{~km}=1.1516 \mathrm{mi}$. SGALES BY 2.

FOR VALUES OF MUF GREATER

THAN 35 ME, MULTIPLY ALL MUF AND FOT

DISTANCE IN KM
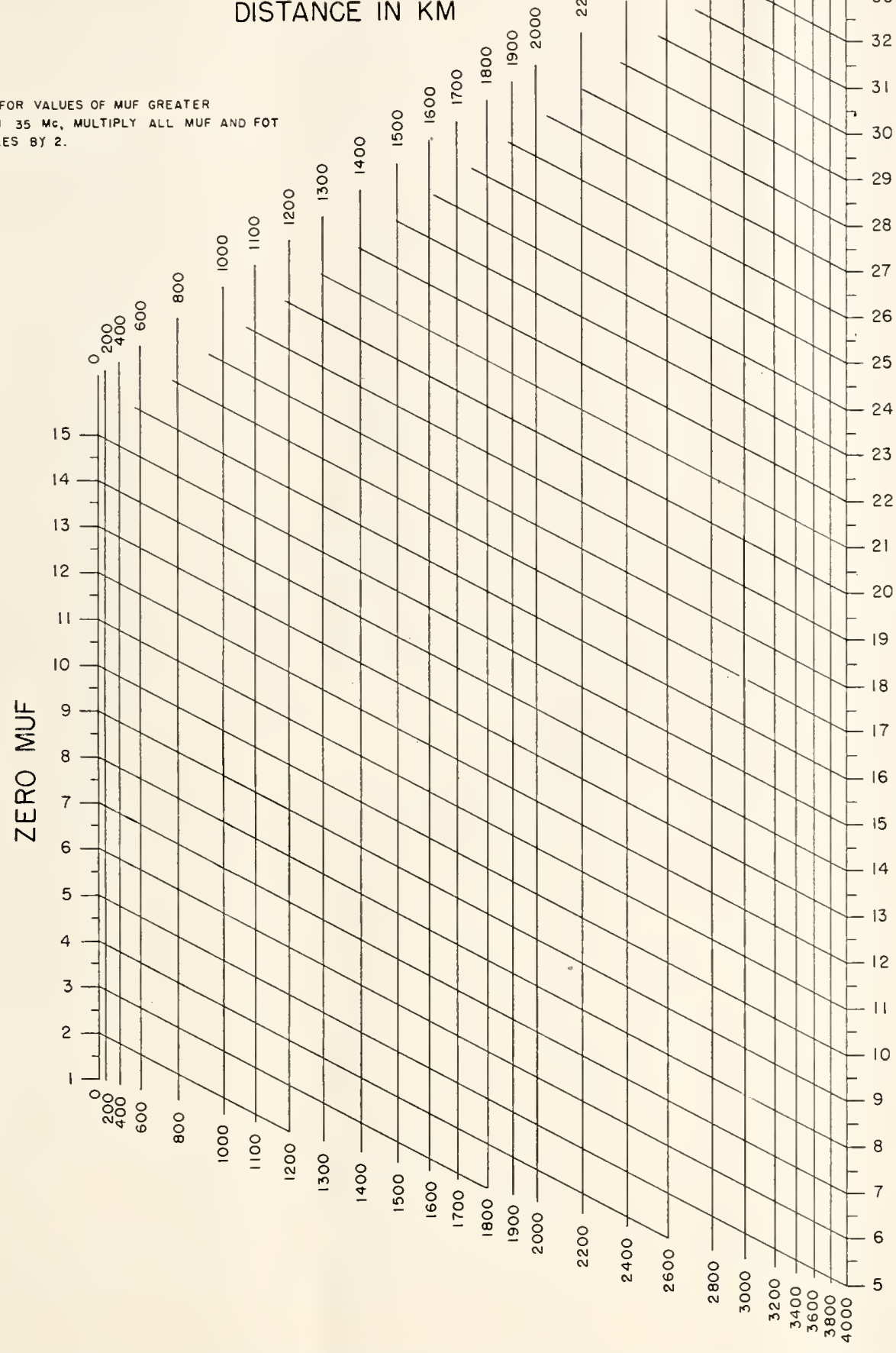

MUF FOT

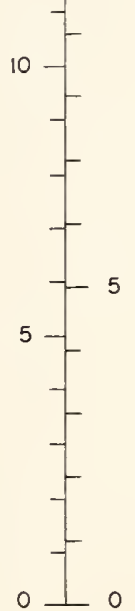

NOMOGRAM FOR TRANSFORMING F2-ZERO-MUF AND F2-4000-MUF TO EQUIVALENT MAXIMUM USABLE FREQUENCIES AT INTERMEDIATE TRANSMISSION DISTANCES; CONVERSION SCALE. FOR OBTAINING OPTIMUM TRAFFIC FREQUENCY (FOT). 


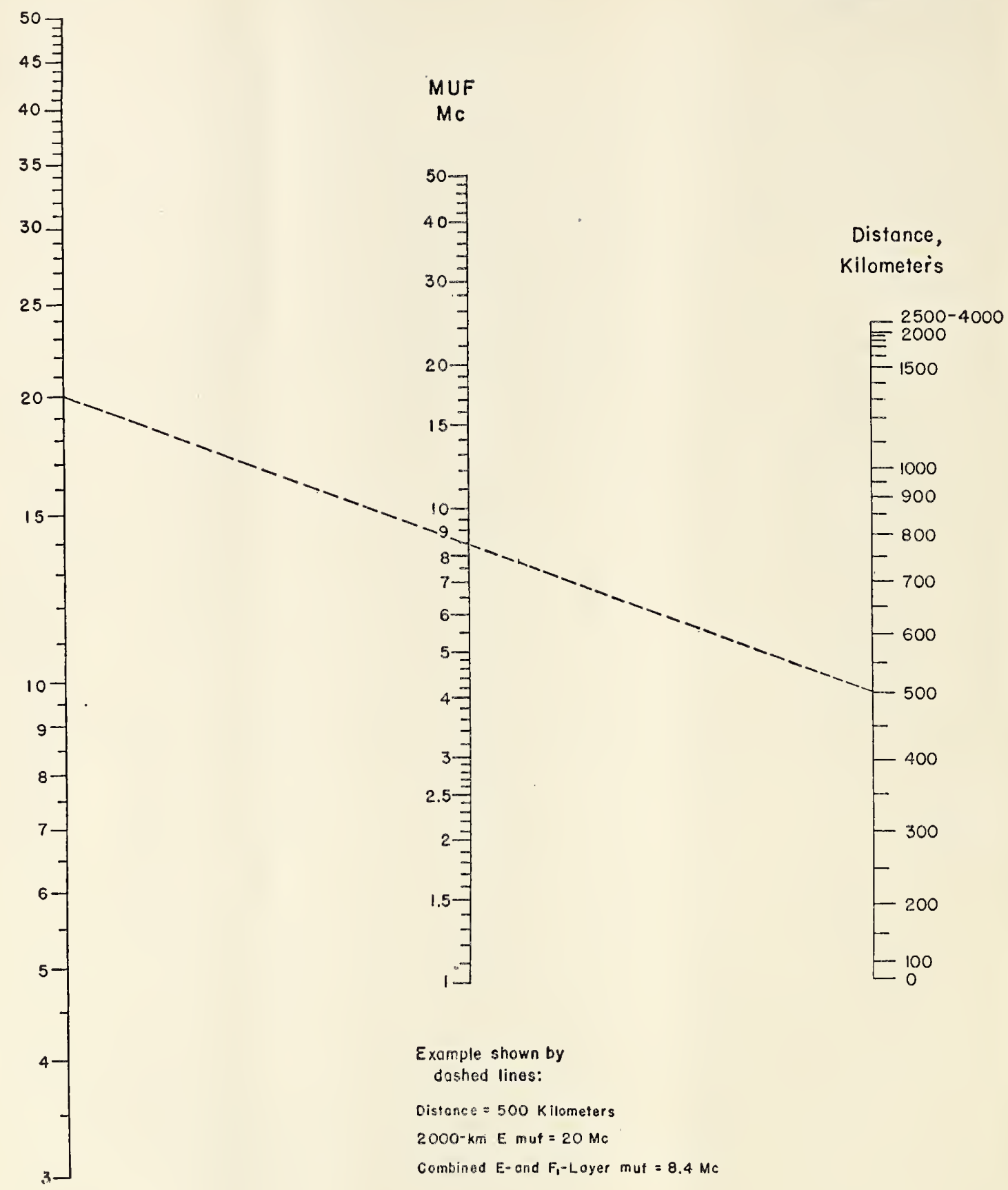




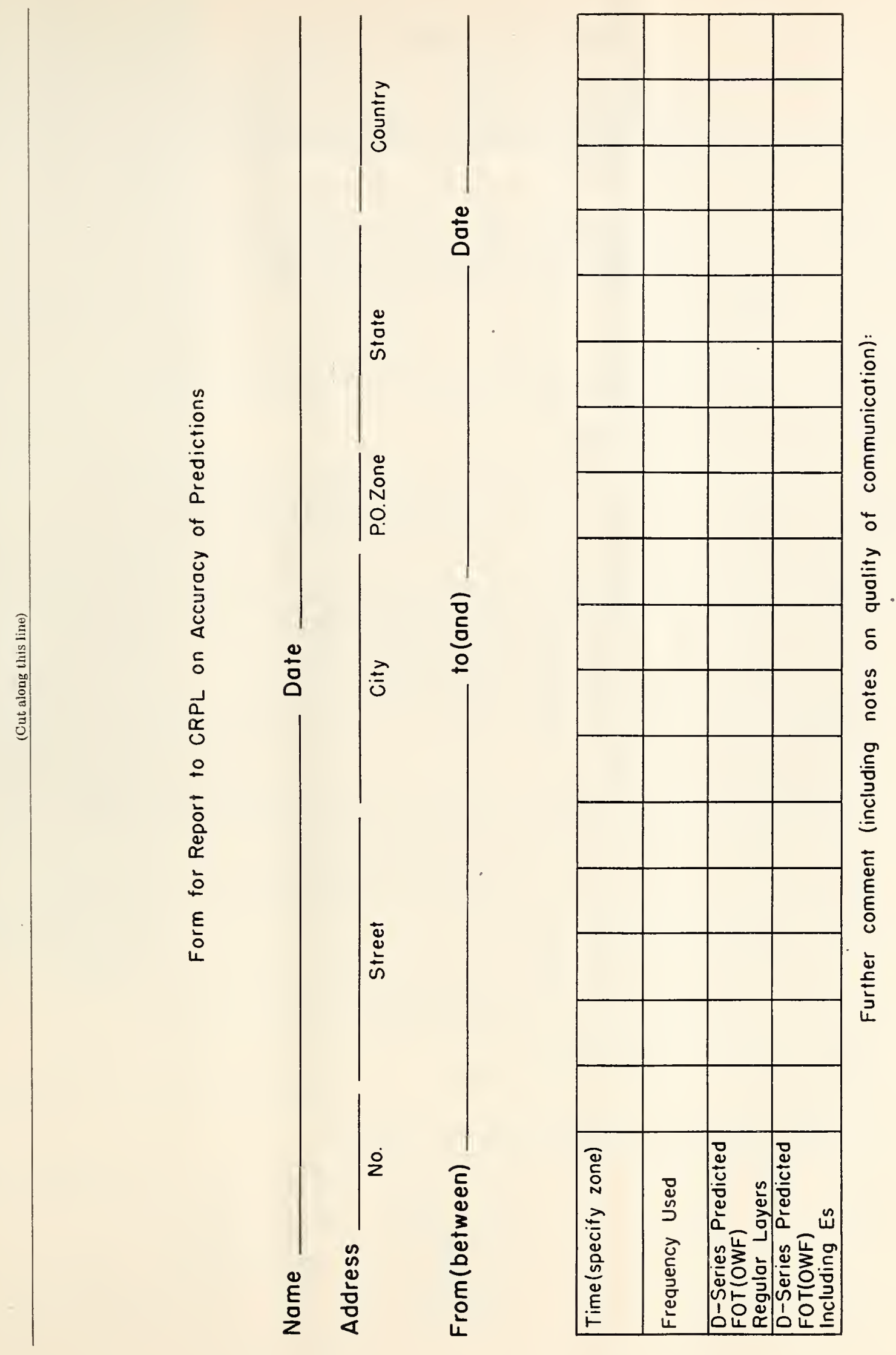




\section{CRPL and IRPL Reports}

[A list of CRPL Section Reports is available from the Central Radio Propagation Laboratory upon request]

Daily:

Radio disturbance warnings, every half hour from broadcast station WWV of the National Bureau of Standards.

Telephoned and telegraphed reports of ionospheric, solar, geomagnetic, and radio propagation data.

Weekly:

CRPL-J. Radio Propagation Forecast (of days most likely to be disturbed during following month).

Semimonthly:

CRPL-Ja. Semimonthly Frequency Revision Factors for CRPL Basic Radio Propagation Prediction Reports.

Monthly:

CRPI-D. Basic Radio Propagation Predictions-Three months in advance. (Dept. of the Army, TB 11-499-, monthly supplements to TM 11-499; Dept. of the Navy, DNC-13-1 ( ), monthly supplements to DNC-13-1.)

CRPL-F. Ionospheric Data.

Quarterly:

*IR PL-A. Pecommended Frequency Bands for Ships and Aircraft in the Atlantic and Pacific

*IRPL-H. Frequency Guide for Operating Personnel.

Circulars of the National Bureau of Standards:

NBS Circular 462. Ionospheric Radio Propagation.

NBS Circular 465. Instructions for the Use of Basic Radio Propagation Predictions.

Reports issued in past:

IR PL-C61. Keport of the International Radio Propagation Conference, 17 April to 5 May 1944.

IRPL-G1 through G12. Correlation of D. F. Errors With Ionospheric Conditions.

IRPL-R. Nonscheduled reports:

R4. Methods Used by IRPL for the Prediction of Ionosphere Characteristics and Maximum Usable Frequencies.

R5. Criteria for Ionospheric Storminess.

R6. Experimental Studies of Ionospheric Propagation as Applied to the Loran System.

- R7. Second Report on Experimental Studies of Ionospheric Propagation as Applied to the Loran System.

R9. An Automatic Instantaneous Indicator of Skip Distance and MUF.

R10. A Proposal for the Use of Rockets for the Study of the Ionosphere.

R11. A Nomographic Method for Both Prediction and Observation Correlation of Ionosphere Characteristics

R12. Short Time Variations in Ionospheric Characteristics.

R14. A Graphical Method for Calculating Ground Reflection Coefficients.

R15. Predicted Limits for F2-layer Radio Transmission Throughout the Solar Cycle.

R16. Predicted F2-layer Frequencies Throughout the Solar Cycle, for Summer, Winter, and Equinox Season.

R17. Japanese Ionospheric Data-1943.

R18. Comparison of Geomagnetic Records and North Atlantic Radio Propagation Quality Figures-October 1943 Through May 1945.

R19. Nomographic Predictions of F2-layer Frequencies Throughout the Solar Cycle, for June.

R20. Nomographic Predictions of F2-layer Frequencies Throughout the Solar Cycle, for September.

R21. Notes on the Preparation of Skip-Distance and MUF Charts for Use by Direction-Finder Stations. (For distances out to $4000 \mathrm{~km}$.)

R22. Nomographic Predictions of F2-layer Frequencies Throughout the Solar Cycle, for December.

R23. Solar-Cycle Data for Correlation with Radio Propagation Phenomena.

R24. Relations Between Band Width, Pulse Shape and Usefulness of Pulses in the Loran System.

R25. The Prediction of Solar Activity as a Basis for the Prediction of Radio Propagation Phenomena.

R26. The Ionosphere as a Measure of Solar Activity.

R27. Relationships Between Radio Propagation Disturbance and Central Meridian Passage of Sunspots Grouped by Distance From Center of Disc.

R28. Nomographic Predictions of F2-layer Frequencies Throughout the Solar Cycle, for January.

R30. Disturbance Rating in Values of IRPL Quality-Figure Scale from A. T. \& T. Co. Transmission Disturbance Reports to Replace T. D. Figures as Reported.

R31. North Atlantic Radio Propagation Disturbances, October 1943 Through October 1945.

R32. Nomographic Predictions of F2-layer Frequencies Throughout the Solar Cycle, for February.

R33. Ionospheric Data on File at IRPL.

R34. The Interpretation of Recorded Values of $f E s$.

R35. Comparison of Percentage of Total Time of Second-Multiple Es Reflections and That of $f E s$ in Excess of 3 Mc.

IRPL-T. Reports on tropospheric propagation:

T1. Radar operation and weather. (Superseded by JANP 101.)

T2. Radar coverage and weather. (Superseded by JANP 102.)

CRPI-T3. Tropospheric Propagation and Radio-Meteorology. (Reissue of Columbia Wave Propagation Group WPG-5.)

*Items bearing this symbol are distributed only by U.S. Navy. They are issued under one cover as the DNC-14 series. 